\title{
STUDIES ON THE RELATIONSHIP OF THE HEPATITIS VIRUS TO PERSISTENT SYMPTOMS, DISABILITY, AND HEPATIC DISTURBANCE ("CHRONIC HEPATITIS SYNDROME") FOLLOWING ACUTE INFECTIOUS HEPATITIS ${ }^{1}$
}

\author{
By JOHN R. NEEFE, 2 JOSEPH STOKES, JR., ROBERT S. GARBER, AND \\ SYDNEY S. GELLIS \\ (From the Nutritional Service of the Department of Pediatrics (Medical School) and of the \\ Gastrointestinal Section (Medical Clinic of the Hospital), University of Pennsylvania)
}

The term "chronic hepatitis" has been suggested by Barker, Capps, and Allen (1) for reference to those patients with infectious hepatitis who fail to recover within 4 months of the onset of the disease. This term also appears to be applicable to those patients with homologous serum hepatitis who fail to recover within 4 months. As used here the word "chronic" refers only to "duration without implication concerning the nature of the pathologic process or the eventual prognosis."

The frequency with which "virus hepatitis" 3 becomes chronic is not known and probably varies with the patient's age, general condition (nutritional and otherwise), management, and possibly with the strain of virus concerned. However, in a series of 431 unselected cases diagnosed as "infectious hepatitis" in the Mediterranean Theater (1), 18 per cent were classified as chronic on the basis of the above definition. Furthermore, under the favorable conditions associated with the study of induced infectious hepatitis in one group of healthy, well-nourished, adequately treated volunteers between the ages of 18 and 32 , approximately 15 per cent failed to recover completely within 4 months, although all achieved complete clinical recovery within one year $(2,3)$. On the basis of these data and the high incidence of acute virus hepatitis during recent years, the occurrence of a relatively large number of such chronic cases (as defined above) might be expected.

1 This investigation was made possible by a grant from the Donner Foundation, Inc., Philadelphia, $\mathrm{Pa}$., and also was aided in part by the Commission on Measles and Mumps, Army Epidemiological Board, Preventive Medicine Service, Office of the Surgeon General, U. S. Army, Washington, D. C.

2 National Research Council Senior Fellow in the Medical Sciences.

3 The term "virus hepatitis" is used to include both infectious hepatitis and homologous serum hepatitis.
Chronic hepatitis presents a number of important medical problems. Recognition frequently may be difficult, particularly in the non-icteric cases, and a lack of knowledge of the factors leading to chronicity has prevented a fundamental approach to its prevention and treatment. Furthermore, the chronic form of the disease may be of importance in the epidemiology of virus hepatitis, particularly when unrecognized.

The relationship of the hepatitis virus to the chronic stage of the disease unfortunately is obscure. A knowledge of this relationship obviously is essential for the clarification of some of the problems mentioned. For this reason, it was considered desirable to attempt to isolate the hepatitis virus from patients with a chronic form of the disease. Suitable materials for study were available from three volunteers with chronic active non-icteric hepatitis observed among a group of volunteers in whom acute infectious hepatitis had been induced under experimental conditions by the oral administration of feces known to contain the virus of infectious hepatitis (virus IH) described in previous reports $(4,5)$. It is the purpose of this preliminary report to describe the results of attempts to demonstrate the hepatitis virus in serum, feces, and liver tissue obtained from these three chronic cases.

\section{MATERIALS AND METHODS}

Source and materials. The histories of the three volunteers with chronic active non-icteric hepatitis have been described elsewhere (3) and do not warrant repetition here. The diagnosis appeared to be unequivocal and was based on the history, symptoms, laboratory evidence of hepatic disturbance, and, in two of the cases, on the histologic findings in liver biopsy specimens obtained 6 and 9 months respectively after the onset of acute hepatitis. The same strain of virus had been used for the induction of acute infectious hepatitis in all three cases. Specimens of feces and serum were collected at intervals through- 
out the course of the disease. The times of collection of the individual serum and feces specimens included in the pools used in the present study are shown in Figures 1, 2 , and 3 in which the results of serial hepatic tests roughly reflect the course of the disease in the three cases. The liver tissue tested for the presence of virus was part of a biopsy specimen obtained surgically from Case 2 (HPZ) at the time indicated in Figure 2 (approximately 6 months after the onset of hepatitis). Serum and feces specimens were frozen within 1 hour after collection. They were stored at $-10^{\circ}$ to $-20^{\circ} \mathrm{C}$. until the time of administration to volunteers, with the exception of a few hours

\section{CHRONIC HEPATITIS-D.C.H.}

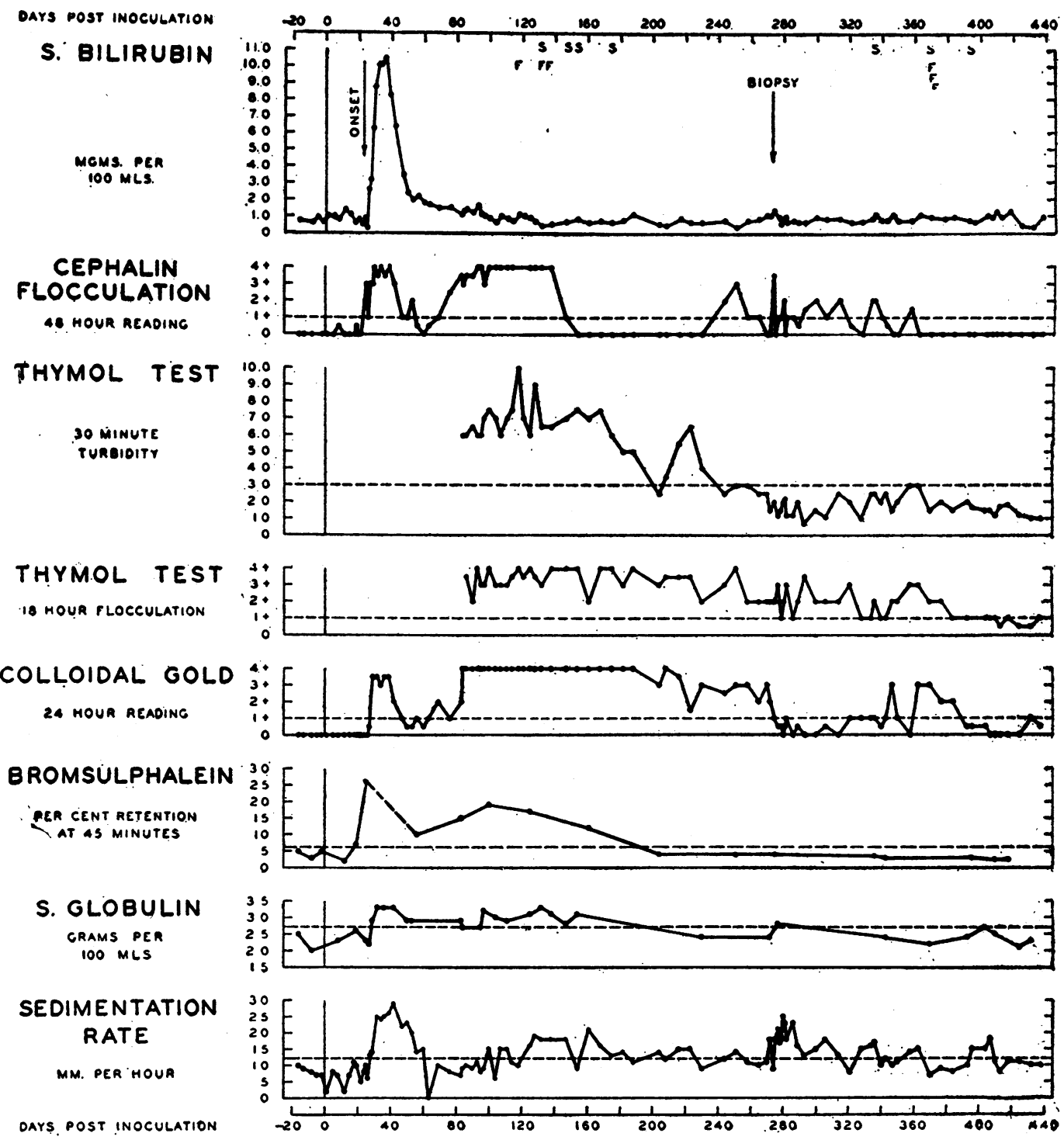

Fig. 1. Results of Serial Hepatic Tests in Voluntere D. C. H.

The "S" and " $F$ " located beneath the time scale at the top of the figure indicate the times when serum (S) and feces (F) specimens were collected. Acute hepatitis had been induced in this subject by the oral administration of a feces preparation known to contain a representative strain (virus IH, $\mathrm{Pa}$.) of infectious hepatitis virus. For approximately one year after the disappearance of jaundice associated with the acute hepatitis, he had persistent symptoms resulting in partial incapacitation. A microscopic examination of the liver biopsy, obtained at the indicated time, revealed the stroma of many of the portal triads, to be infiltrated with excessive lymphocytes, plasma cells, and histiocytes. 


\section{CHRONIC HEPATITIS - H. P. Z.}

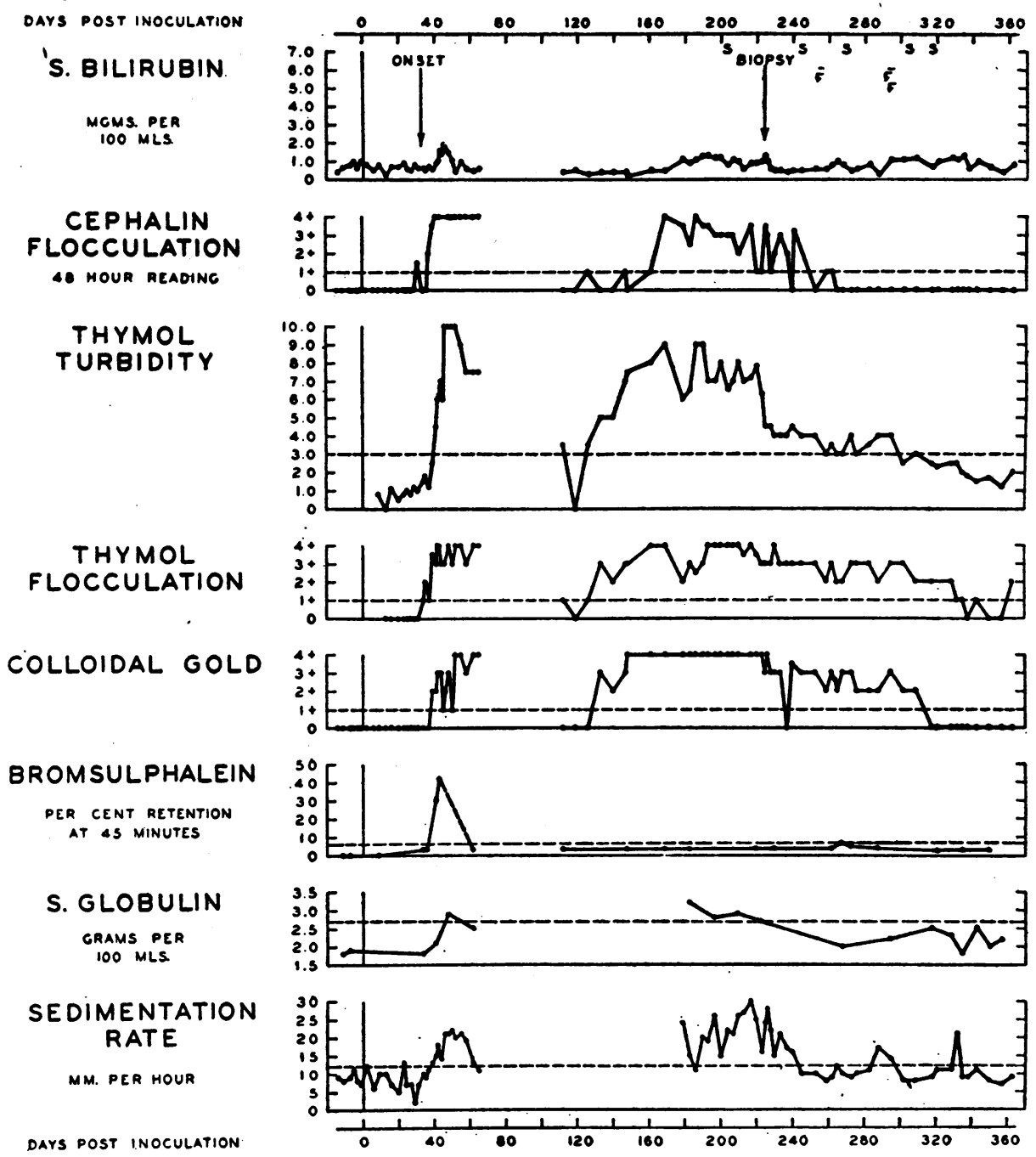

Fig. 2. Results of Serial Hepatic Tests in Voluntere H. P. $Z$.

Acute hepatitis was induced as described in the legend of Figure 1. For other data referable to the figure, see legend of Figure 1. A part of the liver.biopsy obtained at the time indicated was used in the present studies (see text). This volunteer continued to have symptoms and partial disability for approximately 10 months after the onset of the acute attack.

on one day when they were thawed simultaneously, the pools prepared, and then refrozen. The liver tissue was placed in a dry bottle and was frozen within 15 minutes after its surgical removal. It also was stored at $-10^{\circ}$ to $-20^{\circ} \mathrm{C}$. until used.

Preparation of materials: Feces pool 13-14-15 FIH. The feces specimens from the individual cases were thawed and a portion of each was pooled with the others from the same case, yielding pools 13, 14, and 15 respectively. Sufficient distilled water was added to each of these pools to produce, after mixing, the consistency of a thick paste. Additional distilled water then was added and a heavy homogeneous suspension was obtained by thorough mixing in a Waring Blendor. This then was strained through gauze to remove any remaining large particles. Each of the 3 pools $(13,14,15)$ then was cultured (no commonly pathogenic intestinal bacteria were isolated), and, after the culture reports were available, equal portions from each were pooled and mixed to yield feces pool 13-14-15 FIH. The final pool thus included a total of 23 feces specimens obtained 92 to 342 days after the initial onset of hepatitis (Figures 1, 2, and 3.). 


\section{CHRONIC 'HEPATITIS - R. H. M.}

oars. post inogulation

S. BILIRUBIN

Mens pen

100 MLs

CEPHALIN

FLOCCULATION

48 MOUR READING

THYMOL TURBIDITY
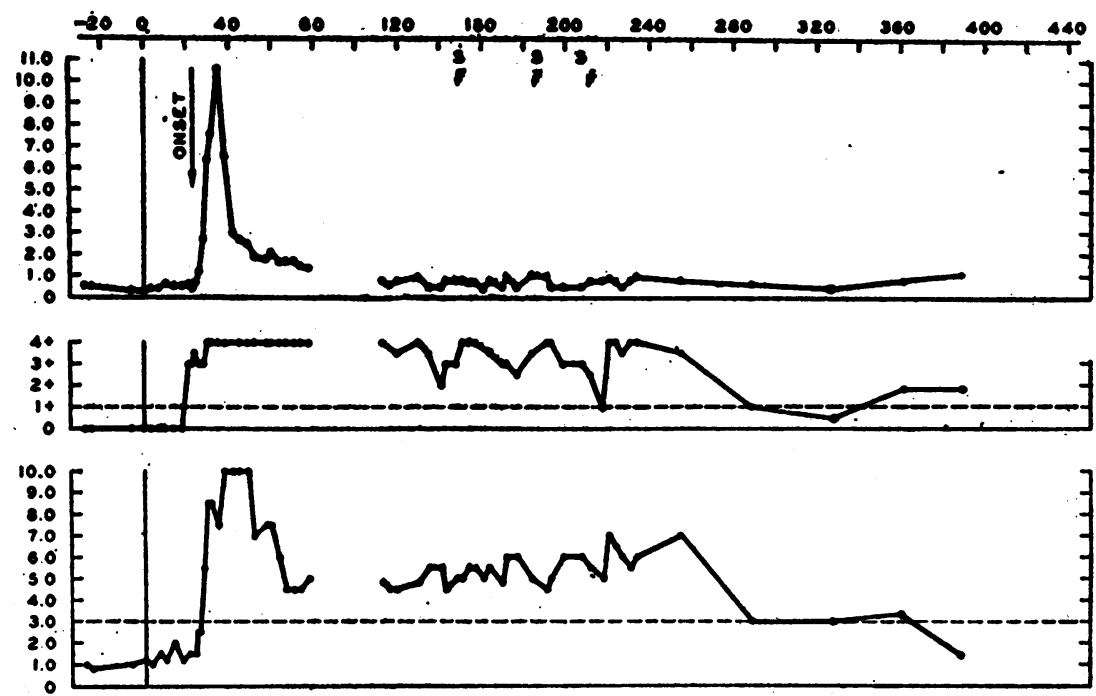

THYMOL FLOCCULATION

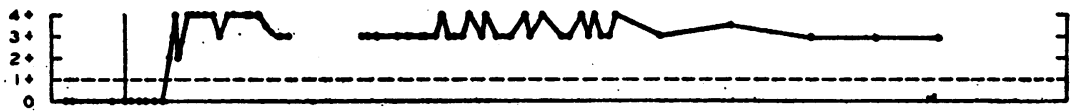

COLLOIDAL GOLD

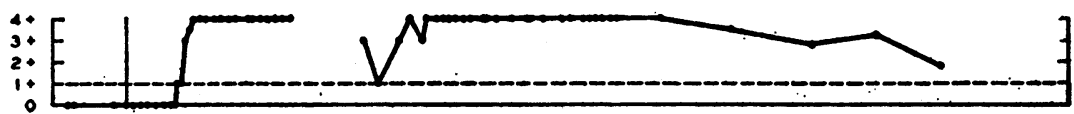

BROMSULPHALEIN

PER CENT RETENTION AT 45 MINUTES

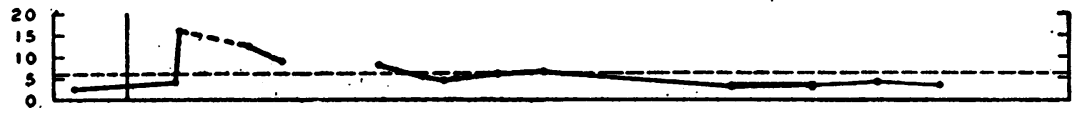

S. GLOBULIN

GRAMS PER 100 MLS.

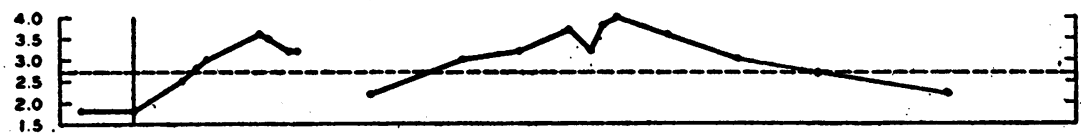

\section{SEDIMENTATION RATE}

MM PER HOUR

OAYS POST INOCULATION.

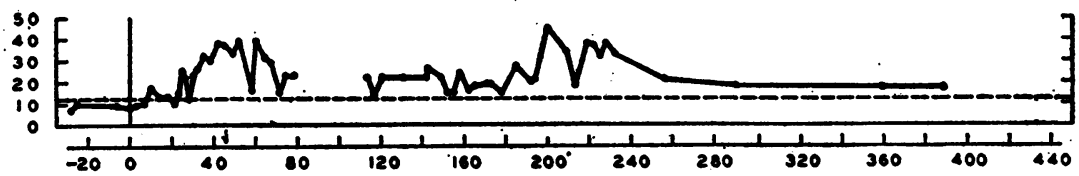

Fig. 3. Results of Serial Hepatic Tests in Volunteer R. H. M.

See legend Figure 1 for the other data referable to this figure. This subject continued to have persistent symptoms and partial disability for approximately 10 months after the onset of acute hepatitis.

Serum pool 1-CSIH. Approximately $2 \mathrm{ml}$. of each serum specimen obtained from 106 to 367 days after the onset of hepatitis were mixed together to form this pool which included a total of 15 serum specimens (Figures 1,2 , and 3 ).

Liver suspension 1-CLIH. The biopsy specimen of the liver tissue, estimated to weight between 100 and 200 mgm., was thawed and promptly was ground with sterile alundum. The ground liver tissue then was suspended in approximately $12 \mathrm{ml}$. of sterile beef heart infusion broth. The suspension was centrifuged for 10 minutes at
2,000 r.p.m. The supernatant then was removed and stored at $-10^{\circ} \mathrm{C}$.

Just prior to its oral administration to the volunteers, the supernatant was thawed and diluted to approximately $100 \mathrm{ml}$. with sterile physiological saline solution and this (liver suspension 1-CLIH) was divided into equal portions $(20 \mathrm{ml}$.) which were ingested by each of the 5 subjects.

The report of Colonel Balduin Lucké, of the Army Institute of Pathology, Washington, D. C., on the microscopic appearance of this liver tissue was as follows: 
"The hepatic structure is preserved but allowance must be made for variations in lobular configuration that are normal at the surface of the liver. The stroma of most portal triads contains a moderate excess of cells, mostly lymphocytes and histiocytes; some triads, however, are entirely normal. No connective tissue proliferation is evident. Occasionally minute foci of cell reaction similar to those of the triads are met within the interior of some lobules. Many liver cells are swollen and appear to be laden with glycogen; these cells are often binucleated. It is probable that they represent regenerated cells. About half of the liver cells seem to have a low glycogen content, suggesting that storage of this material has varied in different parts of the tissue."

Volunteers. All of the men who volunteered as subjects for the study were male inmates of the New Jersey State Prison, Trenton, N. J. Because of statistically significant evidence (2) indicating that susceptibility to the virus of infectious hepatitis used in this study decreased after the age of 26 , and decreased rapidly after the age of 30 , an effort was made to obtain volunteers under 30 years of age. Unfortunately, only a few of the volunteers within this age range could be made available at the time. It was necessary, therefore, to use a number of men who were not within the age range of greatest susceptibility (up to 26 years of age) to this strain of virus. The ages of the 5 men who were inoculated with the feces pool were $23,27,31,32$, and 33 respectively. Those inoculated with the serum pool were $20,29,31,32$, and 39 respectively. Those who received the liver suspension were $21,28,29,34$, and 34 respectively. All were considered to be in good health. None had a history of previous jaundice or presented clinical evidence of hepatic disease prior to inoculation. All of the men were isolated as a group in a special ward provided by the New Jersey State Hospital, Trenton, N. J. The period of isolation began 1 month prior to inoculation and continued for 2 months after inoculation. During this period, the only contacts were with the nurses, the special guards assigned by the prison, the technicians, and the supervising physicians. None of these contacts reported any illness during the period of experiment. Although personal contact between the volunteers was not preventable at meal and recreation times, they were quartered in individual rooms with individual toilet facilities and individual eating utensils were used. Registered nurses were in constant attendance during the isolation period. Following their release from the isolation ward at the New Jersey State Hospital, the men were returned to the New Jersey State Prison where they were followed for an additional 3-month period.

Studies on volunteers. The hepatic studies described in previous reports $(3,6,7)$ were conducted on each subject at frequent intervals both before and after inoculation. Total and prompt direct-reacting ( $\left.1^{\prime}\right)$ serum bilirubin determinations, urine bilirubin and urobilinogen tests, and the cephalin-cholesterol flocculation, colloidal gold, and thymol tests were conducted at least twice weekly during the period of observation. Bromsulphalein tests were done once weekly. Serum total protein, albumin, and globulin were determined at less frequent intervals. Oral temperatures were recorded at least twice daily. With the appearance of any symptoms or laboratory abnormalities, the studies were repeated with greater frequency. After release from the isolation ward, the hepatic tests were continued at 1- to 3-week intervals.

Inoculation of volunteers. On each of 4 successive days, $5 \mathrm{ml}$. of feces pool 13-14-15 FIH was administered orally in chocolate milk to each of 5 volunteers. Each of 5 other volunteers ingested $3 \mathrm{ml}$. (1 man) to $5 \mathrm{ml}$. ( $4 \mathrm{men}$ )

TABLE I

Results in volunteers after ingestion of feces pool 13-14-15 FIH

\begin{tabular}{|c|c|c|c|c|}
\hline $\begin{array}{l}\text { Sub- } \\
\text { jects }\end{array}$ & Age & $\begin{array}{c}\text { Illness } \\
(- \text { to } \\
++++)\end{array}$ & D. A. I. & Remarks \\
\hline \multirow[t]{2}{*}{ J. D. } & \multirow{2}{*}{$\begin{array}{l}31 \\
3\end{array}$} & + & 20 to 28 & Symptoms only \\
\hline & & "t+t & 127 to 137 & $\begin{array}{l}\text { Symptoms, liver ten- } \\
\text { derness, mild hepatic } \\
\text { dysfunction }\end{array}$ \\
\hline R. A. । & 32 & + & 18 to 41 & $\begin{array}{l}\text { Intermittent symp- } \\
\text { toms }\end{array}$ \\
\hline G. S. & 23 & + & 20 to 35 & Symptoms only \\
\hline E. S. & 27 & - & - & - \\
\hline A. $\mathbf{M}$. & 33 & - & - & - \\
\hline
\end{tabular}

Illnesses graded from - (no illness) to ++++ on the basis of the relative severity of symptoms and signs as observed in these subjects. D.A.I. indicates the number of days after inoculation when symptoms were present.

TABLE II

Results in volunteers after ingestion of liver suspension 1-CLIH

\begin{tabular}{l|c|c|c|l}
\hline $\begin{array}{c}\text { Sub- } \\
\text { jects }\end{array}$ & Age & $\begin{array}{c}\text { Illness } \\
(- \text { to } \\
++++)\end{array}$ & D. A. I. & \multicolumn{1}{|c|}{ Remarks } \\
\hline E. Mc. & 29 & + & 22 to 29 & Symptoms \\
\cline { 2 - 4 } & ++++ & 36 to 50 & $\begin{array}{l}\text { Symptoms, plus he- } \\
\text { patic enlargement and } \\
\text { tenderness; no signif- } \\
\text { cant hepatic dysfunc- } \\
\text { tion detected }\end{array}$ \\
\hline T. K. & 21 & + & 26 to 30 & $\begin{array}{l}\text { Symptoms and labor- } \\
\text { atory evidence sug- } \\
\text { gestive of mild he- } \\
\text { patic dysfunction }\end{array}$ \\
\hline M. P. & 28 & + & 28 to 51 & $\begin{array}{l}\text { Intermittent symp- } \\
\text { toms only }\end{array}$ \\
\hline P. S. & 34 & + & 15 to 60 & $\begin{array}{l}\text { Intermittent symp- } \\
\text { toms only }\end{array}$ \\
\hline J. M. & 34 & - & - & - \\
\hline
\end{tabular}

See legend of Table I for other data referable to interpretation of table. 
TABLE III

Results in volunteers after ingestion of serum pool 1-CSIH

\begin{tabular}{l|c|c|c|c}
\hline \hline $\begin{array}{l}\text { Sub- } \\
\text { jects }\end{array}$ & Age & $\begin{array}{c}\text { Illness } \\
(- \text { to } \\
++++)\end{array}$ & D. A. I. & Remarks \\
\hline V. P. & 39 & \pm & 10 to 15 & $\begin{array}{l}\text { Very mild symptoms } \\
\text { only }\end{array}$ \\
\hline E. S. & 31 & \pm & 14 to 26 & $\begin{array}{l}\text { Very mild symptoms } \\
\text { only }\end{array}$ \\
\hline W. H. & 32 & - & - & - \\
\hline A. W. & 20 & - & - & - \\
\hline L. S. & 29 & - & - & - \\
\hline
\end{tabular}

See legend of Table I for other data referable to interpretation of table.

of the undiluted serum pool 1-CSIH, the material being administered in milk. The 5 men of the third group each ingested (in milk) $20 \mathrm{ml}$. of liver suspension 1-CLIH.

Previous experience with the strain of infectious hepatitis virus (virus $\mathrm{IH}$ ) that was used for induction of hepatitis in the three volunteers from which the present materials were obtained had shown it to be highly effective in inducing the apparent disease when administered orally but much less effective when administred parenterally. For this reason, and because of the limited number of volunteers available for these preliminary studies, only the oral route of inoculation was used.

\section{RESULTS}

The results obtained from the oral administration of the feces, liver, and serum preparations are summarized in Tables I, II, and III and are described in detail below.

\section{Feces pool 13-14-15 FIH}

J. D. (AGE 32). Eleven days after inoculation he complained of cramps in the abdomen. On the 16th day, he noted a "slight rash" associated with pruritis. As this was transient, it was not observed by a physician and a reliable description is not available. From the 20th to 28th days inclusive, he complained of nausea, headache, and general malaise. No significant physical findings - were recorded during this period, and no definite evidence of hepatic disturbance was revealed by the various hepatic tests. After the 28th day, he apparently was well until the 127 th day. He had been released from the isolation ward and returned to the New Jersey State Prison on the 70 th day. On approximately the 122nd day, he was released from the prison and went to his home. From the 122nd to 127 th days, he had little sleep and ingested moderate quantities of alcoholic beverages. On the 127th day, he noted extreme malaise. This was associated with chilly sensations and his temperature was found to be $102.8^{\circ} \mathrm{F}$. (oral). He was admitted the next day (128th) to the Hospital of the University of Pennsylvania. At that time, he complained chiefly of weakness, headache, aching of the eyes on movement, anorexia, and pain in the right costovertebral angle. Examination revealed an oral temperature of $102^{\circ} \mathrm{F}$., slight enlargement of the inguinal, axillary, and cervical lymph nodes, and pronounced tenderness in the right upper quadrant and right costovertebral angle. The liver and spleen were not palpable. The symptoms and findings persisted until the 132nd day after which they gradually subsided. By the 137th day, he was asymptomatic and physical examination was negative. The oral temperature varied between $99^{\circ}$ and $101^{\circ} \mathrm{F}$. on the 129 th and 130th days, from normal to $100.4^{\circ} \mathrm{F}$. on the 131 st and 132nd days, and thereafter was normal. He was discharged from the hospital on the 137th day.

The results of the laboratory studies made during this period were as follows: The blood hemoglobin varied between 90 and 95 per cent; the total leukocyte count was 5,000 on the 128 th day and 5,000 on the 131 st day. The differential leukocyte count on the 131st day revealed : neutrophiles-59 per cent, lymphocytes-40 per cent, monocytes-1 per cent. Routine urinalysis consistently revealed no abnormal findings. The hepatic tests gave the following results suggesting the existence of mild hepatic disturbance: The Harrison spot test for urine bilirubin was constantly positive between the 128th and 139th days, the response varying from 1 to $3+$. Urine urobilinogen was somewhat increased, the maximum recorded value being 2.0 Ehrlich units in a morning, 2-hour specimen. Bromsulphalein tests on the 128 th, 129th, 130th and 137th days gave 30 - and 45-minute values (30 minute per cent retention -45 minute per cent retention) of $7 / 4,12 / 11$, $7 / 4$, and $4 / 3$ respectively. The results of the total and prompt direct reacting serum bilirubin determinations, the cephalin-cholesterol flocculation, collodial gold and thymol, and the serum pro- 
tein and cholesterol studies showed no significant variations from the normal.

Typhoid $\mathrm{H}$ and $\mathrm{O}$, paratyphoid $\mathrm{A}$ and $\mathrm{B}$, and brucella abortus agglutinations on the 126th day were negative. A heterophile antibody test (PaulBunnell) on the 137th day (maximal response graded $4+$ ) gave $2+, 1+$, and negative reactions in the $1: 32,1: 64$, and higher dilutions respectively.

Although very cooperative, this subject was anxious to leave the hospital as soon as possible due to the fact that he had been released from prison just prior to onset of this illness. As he felt perfectly well by the 137 th day, it was not possible to detain him for further studies after that time. Two months later, he returned for follow-up studies, having been entirely well during the interval. All hepatic tests were normal and the heterophile antibody test gave a $1+$ reaction in the $1: 64$ dilution, the reaction being negative in the higher dilutions.

R. A. (AGE 32). Eighteen days after inoculation, this subject complained of general malaise and moderate pain in the lumbar area of the back. Between the 19th and 22nd days, he voluntarily remained in bed and complained of malaise, backache, and anorexia. On the 23 rd day, he had intermittent chilly sensations during the evening. These continued during the 24 th and 25 th days and were associated with nausea and one episode of vomiting. Although he then felt relatively normal until the 39th day, his oral temperature varied from $99.8^{\circ}$ to $100.8^{\circ} \mathrm{F}$. between the 34 th and 37 th days. From the 39th to the 41st day, he complained of persistent headache and intermittent nausea. After the 41st day, he remained asymptomatic. No significant physical findings, other than the slight elevation of temperature, were recorded. The hepatic studies revealed no definite evidence of hepatic disturbance. However, the thymol test, which had not given 30 -minute turbidity readings greater than 1.5 units or 18-hour flocculation reactions greater than $1+$ with numerous serum specimens obtained during the month prior to inoculation, gave turbidity readings up to 3.0 units and $2+$ flocculation reactions during the period of symptoms.

G. S. (AGE 23). On the 11th day, the subject complained of slight nausea, headache, and abdominal cramps that persisted for only 24 hours.
From the 20th to the 35th days, he had frequent headaches, intermittent lumbar backache, and mild to moderate anorexia and nausea. On the 25th and 30 th days, he vomited several times. The only laboratory abnormality was the finding of an increased excretion of urine urobilinogen (2.0 E. U.) on the 34th day. He remained well after the 35 th day.

SUbJects E. S. (Age 27) AND A. M. (Age 33). The remaining two volunteers who ingested feces pool 13-14-15 FIH experienced no significant symptoms, and no evidence of hepatic disturbance was revealed by hepatic tests during the period of observation.

\section{Liver suspension (1-CLIH)}

E. MC. (AGE 29). This subject was well until the 22 nd day when, for a period of 24 hours, he reported general malaise, anorexia, nausea, and one episode of vomiting. Although he was relatively asymptomatic between the 23rd and 26th days, symptoms recurred on the 26th day, and persisted till the 29th day. During this period he complained of weakness, general malaise, anorexia, nausea, and pain in the region of the right costovertebral angle. He was relatively free from symptoms between the 29th and 36th days. However, from the 36th to the 50th day, he experienced rather severe symptoms. They included: (1) marked malaise of sufficient intensity to keep him in bed; (2) complete anorexia, severe nausea, and vomiting one or more times daily for a period of approximately 10 days; any attempt to eat solid food was followed by vomiting; (3) headache with considerable orbital pain on movement of the eyes; (4) pain in the right upper quadrant that at times was of sufficient severity to require morphine. He was given daily intravenous infusions of glucose and saline during this period. No significant temperature elevations were recorded until the 48th day when the oral temperature was $100^{\circ} \mathrm{F}$. It fluctuated between $98^{\circ}$ and $100^{\circ} \mathrm{F}$. on the 48th and 49th days. About 2 hours after a plasma transfusion on the 50th day, he had a chill and, during the next few hours, his temperature gradually rose to a maximum of $107^{\circ} \mathrm{F}$. (rectal). The significance of the fever noted on the 48th and 49th days is uncertain as he had received glucose and saline infusions on these days. That of the 50th day appeared to be the result of 
a plasma reaction. With the subsidence of this reaction, all of his symptoms diminished rapidly and he felt relatively normal by the 65 th day.

Physical examination throughout the period of severe symptoms (36th to 50th days) revealed marked tenderness in the right upper quadrant. The liver was enlarged and quite tender. With inspiration, the edge of the liver was easily palpable 3 to $4 \mathrm{~cm}$. below the costal margin. After subsidence of the symptoms, the size of the liver decreased. The spleen was not palpable. No other significant physical abnormalities were detected.

The several blood counts (hemoglobin, total and differential leukocyte counts) made during the period of acute symptoms revealed no significant abnormalities. Hepatic tests revealed no significant abnormalities until the 49th day when the urine gave a positive reaction for urobilinogen in a dilution of 1 to 30 and bromsulphalein retention was 10 per cent at 30 minutes and 3 per cent at 45 minutes. $^{4}$ The following day the 30 - and 45 minute retentions were 40 and 30 per cent respectively. The urine was positive for urobilinogen in dilutions of 1 to 100 and 1 to 150 on the 50th and 51st days. On the 55th day, difficulty was encountered in obtaining a 30-minute blood specimen for the bromsulphalein test. A specimen obtained at 41 minutes revealed 8 per cent retention. The other hepatic tests revealed no significant abnormalities and thereafter all results were within normal limits. The abnormalities mentioned are of doubtful significance in respect to his illness because of their relationship to the reactions from the intravenous infusions. Roentgenological examination of the gastrointestinal tract on the 57 th day revealed no abnormal findings.

T. K. (AGE 21). Between the 26th and 30th days after inoculation, he complained of malaise, mild anorexia, nausea, one episode of vomiting, and headache. These subsided by the 30th day and he remained well thereafter. There were no abnormal temperature elevations.

The hepatic tests during this period revealed a maximum total serum bilirubin of $1.7 \mathrm{mgm}$. per

\footnotetext{
4 With 7 previous bromsulphalein tests performed during the preceding 2 months, retention at 30 and 45 minutes was never greater than trace and $O$ respectively.
}

$100 \mathrm{ml}$. (pre-inoculation maximum $1.2 \mathrm{mgm}$.), a delayed direct qualitative van den Bergh reaction, a maximum thymol turbidity of 4.0 units (maximum pre-inoculation reading-2.5 units), and a maximum 2-hour urine urobilinogen concentration of 6.0 Ehrlich units (maximum preinoculation 1.6) with a positive reaction also being obtained in a urine dilution of 1 to 200 .

J. M. (AGE 34). This subject had no significant symptoms or laboratory manifestations of hepatic disturbance following inoculation.

M. P. (AGE 28). Between the 28th and 51st days following inoculation, he complained of malaise and intermittent rather severe headaches. No other significant symptoms or laboratory manifestations suggestive of hepatic disturbance were present.

P. S. (AGE 34). Fifteen days after inoculation a pruritic rash, slight headache, and an elevation of oral temperature to $100^{\circ} \mathrm{F}$. were experienced. No adequate description of the rash is available as it was observed only by the attending nurse and disappeared in 24 hours before he was seen by a physician. From the 21st to 26th days he was nauseated intermittently, vomited on two occasions, and his appetite was moderately diminished. $\mathrm{He}$ then was relatively asymptomatic until the 39th day when anorexia, abdominal cramps, and headache were present and persisted for approximately 2 days. He again was free from symptoms until the 59th day when, for a 24-hour period, he had anorexia, nausea, and one episode of vomiting. Thereafter he remained well. No significant laboratory evidences suggestive of hepatic disturbance were detected at any time.

\section{Serum pool (1-CSIH)}

None of the 5 men who ingested this serum (V. R., age 39; E. S., 31; W. H., 32; L. S., 29; A. W., 20) developed significant laboratory evidence suggestive of hepatic disturbance following their inoculation. One (V. P.) complained of slight nausea and mild headache between the 10 th and 15 th days. Another (E. S.) between the 14th and 26th days, had malaise, and intermittent mild nausea and headache. The symptoms in both were not sufficient to interfere with their voluntary continuance of their usual activities. 


\section{DISCUSSION}

The results of the present studies permit no definite conclusions concerning the presence of a hepatitis virus in the serum, feces, and liver preparations. Nevertheless, four of the five men who ingested the liver suspension and three of the five who ingested the feces preparation developed illnesses, of mild to moderate severity, after intervals corresponding to the usual incubation period of infectious hepatitis. The symptoms of subject $\mathrm{E}$. $\mathrm{McE}$. (liver suspension) were typical of infectious hepatitis of moderate severity and were associated with enlargement and tenderness of the liver. The only definite laboratory evidence of hepatic disturbance in this subject was observed late in the course of the illness. This was quite transient and could be explained entirely on the basis of febrile reactions that followed intravenous glucose, saline, and plasma. Except for the lack of laboratory evidence of hepatic disturbance, his illness clinically was typical of infectious hepatitis without jaundice.

The symptoms and physical findings in volunteer J. D. (feces preparation) beginning 127 days after inoculation also were typical of mild infectious hepatitis without jaundice. Liver tenderness and laboratory evidence of mild hepatic disturbance were present. This illness began after a period of unaccustomed physical activity, inadequate rest, and ingestion of considerable amounts of alcohol, all following his release after a number of years in prison. Although the possibility that this illness was coincidental and unrelated to the experiment obviously cannot be excluded, it also is quite possible that his symptoms beginning on the 20th day were the result of the hepatitis virus and that his resistance was sufficient to protect him until it was lowered by the activities following his release from the prison. Such activities have been related to an increased incidence of relapse in infectious hepatitis.

The illnesses of the other men were mild. The symptoms and the interval between inoculation and their onset were similar to the symptoms and incubation period of infectious hepatitis. However, evidences of hepatic disturbance either were absent or minimal. In other volunteers with symptoms of comparable and even less severity due to hepatitis resulting from inoculation with this strain of virus, as obtained from acute cases, the illness usually has been associated with fever, and hepatic tests consistently have revealed evidence of marked hepatic disturbance. If these illnesses are considered to be due to a hepatitis virus in the materials obtained from the volunteers with chronic hepatitis, the difference in the manifestations observed in these volunteers from those observed in others inoculated with materials from acute cases must be explained. Some change in the virus itself, a difference in the resistance of the volunteers used, or both possibly could account for the difference. Unfortunately, the volunteers available at the time of the present experiment did not include persons in the age groups most susceptible to the strain of virus concerned. Previous studies (2) have shown that the age range of greatest susceptibility to this strain of virus was from 6 to 25 , the incidence in exposed persons over this age being much lower. Furthermore, with the more marked decrease in incidence observed after the age of 30 , the incidence of hepatitis without jaundice in those over this age who acquired the disease increased from 26 per cent in the 10 to 30 age group to 66 per cent of those over 30 . Of the 15 volunteers available for the present study, only 3 ( 1 in each group of five) were under 25,4 were between 25 and 30 , and 8 were over 30 years of age. It is possible, therefore that the illness observed in these volunteers represented the response of relatively resistant hosts to the hepatitis virus. On the other hand, it also is possible that, in the volunteers with chronic non-icteric hepatitis, some modification of the virus had occurred. However, lacking any specific serological or other test for the hepatitis virus, conclusions regarding the significance of the present results must be deferred. It is hoped that additional volunteers will become available for further tests of the materials used in the present study and of materials obtained from the present subjects during their etiologically obscure illnesses. In addition to the possible influence of factors mentioned above, the failure of serum pool 1-CSIH to produce any significant manifestations suggesting the presence of the hepatitis virus also could have been due either to the absence of the virus in the pool or to the presence, in some of the specimens, of neutralizing substances which inactivated the virus. Thus, the 
negative results with this serum pool do not necessarily indicate that the virus was absent from all of the individual specimens.

\section{SUM MARY AND CONCLUSIONS}

Serum and feces specimens and liver tissue (biopsy) were obtained from 3 subjects who had persistent symptoms and other evidence of continued hepatic disturbance (chronic nonicteric hepatitis) following acute hepatitis that had been induced by oral inoculation with a known strain of "infectious hepatitis" virus. In an attempt to clarify the relationship of the hepatitis virus to the persistent symptoms and continued hepatic disturbance, volunteers were inoculated orally with materials collected from 3 to 12 months after the onset of the disease. Following ingestion of the feces preparation, 3 of the 5 volunteers developed mild illnesses after 18 to 20 days. Likewise, 4 of the 5 volunteers developed illnesses of mild to moderate severity 15 to 36 days after ingestion of a suspension of the liver tissue. None of the 5 volunteers who ingested the serum pool developed significant illness during a 5-month period of observation. The symptoms and manifestations of those who became ill included two or more of the following: malaise, headache, anorexia, nausea, vomiting, abdominal cramps, and pain in the right upper quadrant. Two presented tenderness in the liver area and, in one of these, the liver became moderately enlarged.

In spite of moderately severe symptoms in two of the cases, laboratory evidences of hepatic disturbance in all cases either were absent or minimal. None developed overt jaundice. The intervals between inoculation and onset and the clinical manifestations were compatible with mild infectious hepatitis without jaundice, particularly in two of the cases. The laboratory evidences of hepatic disturbance usually associated with mild hepatitis, however, were not present. Although no other ex- planation for the illnesses is apparent, their exact nature and their relationship to the materials used for inoculation are uncertain. Factors of possible importance in interpretation of the results are discussed.

\section{ACKNOWLEDGMENT}

The authors wish to express their appreciation and gratitude for the contribution of those inmates of the New Jersey State Prison, Trenton, N. J., who volunteered as subjects for the investigation. The assistance and cooperation of the administrative staffs of the Department of Institutions and Agencies, State of New Jersey, the New Jersey State Prison, and the New Jersey State Hospital, Trenton, N. J., also are gratefully acknowledged as is the technical assistance of $\mathrm{Mr}$. and Mrs. Charles Ming and Mr. Ewing Joiner in the conduct of the laboratory studies.

\section{BIBLIOGRAPHY}

1. Barker, M. H., Capps, R. B., and Allen, F. W., Chronic hepatitis in the Mediterranean theater. J. A. M. A., 1945, 129, 653.

2. Neefe, J. R., Recent advances in the knowledge of virus hepatitis. Med. Clin. N. America, 1946 (November-Philadelphia No.), 1407.

3. Neefe, J. R., Results of hepatic tests in chronic hepatitis without jaundice. Gastroenterology, 1946, 7, 1.

4. Neefe, J. R., and Stokes, J., Jr., An epidemic of infectious hepatitis apparently due to a water borne agent. J. A. M. A., 1945, 128, 1063.

5. Neefe; J. R., Gellis, S. S., and Stokes, J., Jr., Homologous serum hepatitis and infectious (epidemic) hepatitis; studies in volunteers bearing on immunological and other characteristics of the etiological agents. Am. J. Med., 1946, 1, 3.

6. Neefe, J. R., Stokes, J., Jr., and Gellis, S. S., Homologous serum hepatitis and infectious (epidemic) hepatitis; experimental study of immunity and cross immunity in volunteers, a preliminary report. Am. J. Med. Sci., 1945, 210, 561.

7. Neefe, J. R., and Reinhold, J. G., Laboratory aids in the diagnosis and management of infectious (epidemic) hepatitis; analysis of results obtained in 34 volunteers during the early and convalescent stages of induced hepatitis. Gastroenterology, 1946, 7, 393. 